\title{
Bioactivity and constituents of several common seaweeds
}

\author{
ZHANG Yi ${ }^{1,2^{*}}$, HAN JinYuan $^{1}$, MU Jun ${ }^{1 *}$, FENG Yan ${ }^{1}$, GU XiaoJie $^{1} \&$ JI YuanXi ${ }^{1}$ \\ ${ }^{1}$ School of Environmental and Chemical Engineering, Dalian Jiaotong University, Dalian 116028, China; \\ ${ }^{2}$ School of Life Science and Biotechnology, Dalian University of Technology, Dalian 116024, China
}

Received May 2, 2012; accepted December 19, 2012

\begin{abstract}
Bioactivity and constituents of 8 common seaweeds from Dalian intertidal zone of northern Yellow Sea were investigated. In the anti-methicillin-resistant Staphylococcus aureus (MRSA) test, Symphyocladia latiuscula and Enteromorpha intestinalis showed obvious activities with MICs much lower than $1.0 \mathrm{mg} \mathrm{mL}^{-1}$. In the DNA damage repair test (DDRT), Chondrus ocellatu showed selective inhibitory activity against the DNA repair-defective E. coli strain vs. the wild-type E. coli strain; while Sym. latiuscula, Enteromorpha intestinalis and Sar. kjellmanianum showed significant anti-E. coli activity with MICs of $64-128 \mu \mathrm{g} \mathrm{mL} \mathrm{m}^{-1}$. In the anti-Pyricularia oryzae test, Sym. latiuscula and Rh. confervoides strongly inhibited the germination of the spores of $P$. oryzae on agar plate. In the brine shrimp larvicidal test, Sym. latiuscula, Rh. confervoides and Sar. kjellmanianum exhibited potent toxicity against brine shrimp larvae, with $\mathrm{LC}_{50}$ much lower than $1 \mathrm{mg} \mathrm{mL}^{-1}$. The HPTLC analysis revealed their diversified secondary metabolites. The HPLC-DAD-MS analysis of the strongest species Sym. latiuscula and database searching showed that it can produce quite diversified metabolites, including halogenated ones, some of which may be new natural products. The results demonstrated the potentials of these seaweeds in the development of new antibiotics, antitumor drugs, agricultural fungicides and pesticides.
\end{abstract}

saweeds, biomass, antibacterial, antifungal, larvicidal, HPTLC, HPLC-DAD-MS

Citation: Zhang Y, Han J Y, Mu J, et al. Bioactivity and constituents of several common seaweeds. Chin Sci Bull, 2013, 58: 2282-2289, doi: 10.1007/s11434$013-5745-y$

Macroalgae are important primary producers of marine and coastal ecosystem and are also useful medicine and pesticide resources due to their potentials in accumulating large quantities of bioactive metabolites [1]. As is known to all, algal diversity and biomass depend on the environmental factors such as temperature, light, and nutrition, which can be influenced by human activities (e.g. introducing species and pollutions in the form of heat and eutrophication). Therefore, it is important to investigate and utilize the algal resources in coastal zones.

Dalian, an important harbor and industrial city, is located on the tip of the Liaodong Peninsula, between China's inner Bohai Sea and the north Yellow Sea. Its marine ecological environment is influenced by strong sea currents and rivers, which provides diversified habitats for seaweeds and also

*Corresponding authors (email: hubeizhangyi@163.com; mujun1971@126.com) brings about human influences. In this article, we evaluated the biomass and their biomedical and agrichemical potentials as new antibiotics, antitumor drugs, agricultural fungicides, and pesticides in some common seaweeds from Dalian coastline by determining several bioactivities of them, including anti-methicillin-resistant Staphylococcus aureus (MRSA), anti-Escherichia coli DNA repair-defective/wildtype strains, anti-Pyricularia oryzae, and anti-brine shrimp (Artemia parthenogenetica L.) larvae.

\section{Materials and methods}

\subsection{Materials and biomass calculation}

Eight species of seaweeds were collected in the intertidal zone of Fujiazhuang Beach (121 $\left.{ }^{\circ} 36^{\prime} 13.82^{\prime \prime} \mathrm{E}, 38^{\circ} 48^{\prime} 36.66^{\prime \prime} \mathrm{N}\right)$ of Dalian in July of 2009, as shown in Table 1 . These 
Table 1 Biomass and habitats of seaweeds under investigation

\begin{tabular}{lcc}
\hline \multicolumn{1}{c}{ Species } & Biomass $\left(\mathrm{g} \mathrm{m}^{-2}\right)$ & Habitats \\
\hline Chlorophyta & & \\
Ulva pertusa & 44.9 & Middle intertidal zone \\
Cladophora fascicularis & 21.1 & Higher intertidal pools \\
Enteromorpha intestinalis & 39.1 & Higher intertidal zone \\
Rhodophyta & & \\
Chondrus ocellatus & 37.2 & Lower intertidal zone \\
Rhodomela confervoides & 25.5 & Middle intertidal pools \\
Symphyocladia latiuscula & 8.1 & Lower intertidal zone \\
Phaeophyta & & \\
Undaria pinnatifida & 26.5 & Lower intertidal zone \\
Sargassum kjellmanianum & 41.8 & Middle intertidal pools \\
\hline
\end{tabular}

species were selected for their remarkably higher occurrence frequency. Their biomasses were calculated by taking the average weight of air-dried samples collected randomly from five quadrates in their habitats for unit area of $1 \mathrm{~m}^{2}$ [2]. They were identified by Professor Hongwei Wang, an expert on algal taxonomy in School of Life Sciences, Liaoning Normal University.

\subsection{Indicator organisms for bioassay}

DDRT strains (E. coli strains AB1157 as wild type and AB3027 with defect in DNA damage repair) were provided by E. coli Genetic Stock Center, Yale University, Methicillin-resistant Staphylococcus aureus (MRSA) strain came from Library of Strains of Dalian Friendship Hospital. Pyricularia oryzae was from the Library of Strains of Chinese Academy of Agricultural Sciences. Brine shrimp eggs (Artemia parthenogenetica L.) were collected at Fuzhou Bay Saltworks of Bohai Sea.

\subsection{Extraction of seaweed}

The seaweed samples were air dried and extracted with 100 $\mathrm{mL}$ of methanol per $20 \mathrm{~g}$ of sample for $24 \mathrm{~h}$ at room temperature. Then the extracts were filtrated, rotary evaporated in vacuum at $45^{\circ} \mathrm{C}$, and finally dissolved in $3 \mathrm{~mL}$ of methanol.

\subsection{Anti-MRSA activity test}

The preliminary screening was performed using paper disk diffusion method with the dose of $30 \mu \mathrm{L}$ extract/disk [3]. The re-screening was performed using MIC method [4]. The test concentration covered the range from 0.0005 to 1.024 $\mathrm{mg} \mathrm{mL} \mathrm{m}^{-1}$.

\subsection{Brine shrimp lethality test}

The brine shrimp lethality test can reflect samples' toxicity against brine shrimp larvae, and the results have a high correlation with antitumor tests. It also can be used as a preliminary screening model for agricultural pesticides. The experimental method used was similar to that in our previous study [5]. In the test, the concentration gradients were set to be $1.024,0.512,0.256,0.128,0.064,0.032,0.016$, $0.008,0.004,0.002,0.001$, and $0.0005 \mathrm{mg} \mathrm{mL}^{-1}$. Then, the semi-lethal concentrations $\left(\mathrm{LC}_{50}\right)$ were calculated from the lethal curve fit by polynomial regressions [5].

\subsection{Growth inhibition test of Pyricularia oryzae}

Pyricularia oryzae is the pathogen of rice, which can be used to screen agricultural fungicides. Furthermore, Kobayashi et al. [6] found that $P$. oryzae's spore germination or hyphal dysmorphism was associated with anti-tumor activity, and is often used to screen antitumor drugs.

Plate confrontation method and spore spreading method were adopted in present study.

In plate confrontation method, $P$. oryzae was inoculated at the center of each Petri dish containing Sabouraud's medium and cultivated at $30^{\circ} \mathrm{C}$ till the colony reached $1 \mathrm{~cm}$ in diameter. Then air dried paper disks loaded with samples at the dose of $30 \mu \mathrm{L}$ extract/disk were placed $1 \mathrm{~cm}$ from the edge of the colonies. The plates were incubated at $30^{\circ} \mathrm{C}$ for 24-48 $\mathrm{h}$ and the inhibition of mycelium growth was observed.

In spore spreading method, $P$. oryzae was first cultured on Petri dished for $10 \mathrm{~d}$ at $30^{\circ} \mathrm{C}$ and then the spore suspension was harvested by scraping mycelia with a sterile blade over the surface of the plate containing $15 \mathrm{~mL}$ of sterile water. Afterwards, the crude suspension was filtrated with three layers of sterile gauze to give pure spore suspension. The $100 \mu \mathrm{L}$ of this suspension was spread onto the surface of each Sabouraud's culture plate. The paper disks with samples at dose of $30 \mu \mathrm{L}$ extract per disk were air dried and placed onto the pre-coated plates. The results were expressed as the diameter of inhibition zones observed and measured after incubation at $30^{\circ} \mathrm{C}$ for $24-48 \mathrm{~h}$.

\subsection{DNA damage repair test}

DNA damage repair test (DDRT) is mainly used to detect active substances with DNA damaging ability. This test, using two E. coli strains, AB1157 for wild type and AB3027 with defect in DNA damage repair [7], consisted of preliminary screening and re-screening.

The preliminary screening used AB3027 strain and was performed by paper disk diffusion method [3]. On each piece of filter paper, the dose was $30 \mu \mathrm{L}$ extract/disk.

The re-screening used both two E. coli strains and was performed by MIC method [4], in which the test concentration covered the range from 0.0005 to $1.024 \mathrm{mg} \mathrm{mL}^{-1}$.

The selectivity of inhibition was calculated by ratio between MIC against AB1157 and MIC against AB3027 and 
was used to assess if the sample had potential DNA damaging ability.

\subsection{HPTLC analysis}

For these samples, $20 \mu \mathrm{L}$ of each $\left(20 \mathrm{mg} \mathrm{mL}^{-1}\right)$ was applied on high-performance thin-layer chromatographic plates (HPTLC silica gel 60 F254, Germany) with a capillary. Then the HPTLC plate was developed by a mixture of $\mathrm{CHCl}_{3} / \mathrm{MeOH}(10: 1, \mathrm{v} / \mathrm{v})$. Afterwards, the plate was colorized by $\mathrm{H}_{2} \mathrm{SO}_{4}$-anisaldehyde reagent at $105^{\circ} \mathrm{C}$ for $2 \mathrm{~min}$ and by acidic $\mathrm{FeCl}_{3}$ ethanol solution at room temperature for 5 min, respectively. The images were scanned as results.

\subsection{HPLC-DAD-MS analysis}

Symphyocladia latiuscula, as the species with strong bioactivities in all the four assays, was analyzed by HPLC-DADMS. The experiment was performed on an Agilent 1200 HPLC-DAD-MS apparatus with an Ultra Trap System XCT 6330 LC/MS detector. Stationary phase: Nucleosil 100 C18, $3 \mu \mathrm{m}, 100 \times 2 \mathrm{~mm}$ ID; equipped with a guard column, $10 \times 2$ $\mathrm{mm}$ ID, same stationary phase. Mobile phases: $\mathrm{A}=0.1 \%$ formic acid, $\mathrm{B}=$ acetonitrile with $0.06 \%$ formic acid; gradient was from $10 \%$ B to $100 \%$ B in $15 \mathrm{~min}$ and $100 \%$ B to the end; flow rate: $400 \mu \mathrm{L} \mathrm{min}{ }^{-1}$; column temperature: $40^{\circ} \mathrm{C}$. MS condition: mode: ESI, positive and negative, alternating; capillary voltage: $3.5 \mathrm{kV}$; temperature: $350^{\circ} \mathrm{C}$. The injection volume was $10 \mu \mathrm{L}\left(5 \mathrm{mg} \mathrm{mL}^{-1}\right)$.

\section{Results}

\subsection{Biomass and distribution}

The sampling and calculation showed that in July of 2009 (Table 1), the eight common seaweeds growing at rocky intertidal zone of Fujiazhuang Beach all produced biomass over $20 \mathrm{~g} \mathrm{~m}^{-2}$, except Symphyocladia latiuscula. In the higher intertidal zone, Enteromorpha intestinalis and Cladophora fascicularis were dominant species. In the middle intertidal zone, Ulva pertusa, Sargassum kjellmanianum, and Rhodomela confervoides contributed the most to biomass. For the lower intertidal zone, Chondrus ocellatus, Undaria pinnatifida, and Sym. latiuscula were the dominant species. The results reflected the biomass production and biodiversity of common seaweeds in this coastal area. According to Shao and Li's report [8], some species, including Ch. ocellatus, En. intestinalis, and Ul. pertusa, have also become the dominant species in most sea areas, probably due to their adaptability to environmental changes caused by human activities (e.g. global warming and eutrophication).

In the development of new marine drugs, sustainable supply of drugs resources is always a bottleneck. Compared to some invertebrates such as sponges and corals, seaweeds, especially those with large biomass, may be a more realistic pharmaceutical resource. Thus, the biomass of seaweeds, naturally occurring or increased due to human activities, should be considered for the development of new medicines or agrichemicals. The potential of seaweeds as new drugs is shown by the following bioassays.

\subsection{Anti-MRSA activity test}

Methicillin-resistant Staphylococcus aureus (MRSA) is an important cause of bacteremia with an increasing incidence worldwide and also a much studied target organism in new drug discovery [9].

In the present investigation, some seaweed samples showed remarkable anti-MRSA potentials (Table 2). In the preliminary screening, Sym. latiuscula showed the strongest activity with the inhibition zone up to $32 \mathrm{~mm}$ in diameter. Rh. confervoides, Ch. Ocellatus and Sar. kjellmanianum also showed powerful inhibitory activity; while $\mathrm{Cl}$. fasciculari, En. Intestinalis and Un. pinnatifida only showed moderate activity. In re-screening, Sym. latiuscula and En. intestinalis both exhibited strong anti-MRSA activity with MICs much lower than $1 \mathrm{mg} \mathrm{mL}^{-1}$. The improved activity of En. intestinalis in the re-screening might be due to its possible active constituents with low polarity, which was difficult to diffuse and take effect in paper disk method but easier to show activity in broth microdilution method. In addition, the remaining five seaweeds also showed moderate activities in re-screening with MICs of about $1 \mathrm{mg} \mathrm{mL}^{-1}$, which are comparable to those in other reports on antimicrobial activities of seaweed extracts [10]. Therefore, most of these seaweeds may be used as sources of new antibiotics against drug-resistant bacteria.

\subsection{Growth inhibition test of Pyricularia oryzae}

In the screening of these seaweeds for their inhibitory activity against $P$. oryzae, two methods were applied (Table 2). In plate confrontation method, none of these seaweeds showed inhibitory activity, indicating that these samples can not inhibit the growth of $P$. oryzae mycelium. However, in spore spreading method, Sym. latiuscula and Rh. confervoides showed inhibition zones with diameter of 35 and 20 $\mathrm{mm}$, respectively. The results indicated their strong inhibitory activity against spore germination of $P$. oryzae. The rest of the seaweeds did not exhibit remarkable activity.

\subsection{Brine shrimp lethality test}

As a simple, fast and cheap model, brine shrimp lethality test has been widely used in the screening for antitumor drugs and pesticides $[11,12]$. This test was also employed in the current study, and the results showed that three species, Rh. confervoides, Sar. Kjellmanianum and Sym. latiuscula, exhibited strong toxicity with lethality ratio of $100 \%$ in the 
Table 2 The bioactivity against MRSA and Pyricularia oryzae of seaweeds

\begin{tabular}{|c|c|c|c|c|}
\hline \multirow[b]{2}{*}{ Species } & \multicolumn{2}{|c|}{ Inhibitory activity against MRSA } & \multicolumn{2}{|c|}{ Inhibition against $P$. oryzae } \\
\hline & $\begin{array}{c}\text { Inhibition zone in } \\
\text { preliminary screening } \\
(\Phi, \mathrm{mm})\end{array}$ & $\begin{array}{l}\text { MIC in re-screening } \\
\quad\left(\mathrm{mg} \mathrm{mL}^{-1}\right)\end{array}$ & $\begin{array}{c}\text { Diameter of Inhibition zone } \\
\text { in Plate confrontation } \\
\text { method }(\mathrm{mm})\end{array}$ & $\begin{array}{c}\text { Diameter of Inhibition zone } \\
\text { in Spore spreading } \\
\text { method (mm) }\end{array}$ \\
\hline Ulva pertusa & $7.5 \pm 0.7$ & 8.192 & - & - \\
\hline Cladophora fascicularis & $8.0 \pm 0.0$ & 1.024 & - & - \\
\hline Enteromorpha intestinalis & $8.0 \pm 0.0$ & 0.512 & - & - \\
\hline Chondrus ocellatus & $10.5 \pm 0.7$ & 1.024 & - & - \\
\hline Rhodomela confervoides & $12.0 \pm 0.0$ & 1.024 & - & $20.0 \pm 1.0$ \\
\hline Symphyocladia latiuscula & $32.0 \pm 0.0$ & 0.256 & - & $35.0 \pm 2.0$ \\
\hline Undaria pinnatifida & $9.0 \pm 0.0$ & 1.024 & - & - \\
\hline Sargassum kjellmanianum & $10.5 \pm 0.7$ & 1.024 & - & - \\
\hline
\end{tabular}

preliminary screening using $40 \mu \mathrm{L}$ of extract and $\mathrm{LC}_{50}$ of 287,354 , and $430 \mu \mathrm{g} \mathrm{mL}^{-1}$, respectively, in the quantitative re-screening (Figure 1). Therefore, these seaweeds may be used to develop new antitumor agents and pesticides since many previous reports have displayed good correlation between the results of brine shrimp lethality test and antitumor or anti-pest assays [13].

\section{$2.5 \quad$ E. coli DDRT}

Application of DDRT model in antitumor pre-screening is based on the mechanism that many anticancer drugs act by damaging DNA. Two E. coli strains, AB1157 as wild type and AB3027 with defect in DNA damage repair, were used in this test. Therefore, if a sample showed anti-tumor activity via the mechanism of DNA damage, stronger inhibition would be observed against AB3027 than against AB1157.

In preliminary screening (Table 3), Sym. latiuscula, En. intestinalis, Ch. ocellatus and Sar. kjellmanianum showed inhibitory activity against AB3027(-) strain. In the rescreening, the selectivity value of $C h$. Ocellatus reached 2, indicating that its inhibitory activity against the defect-type (-) E. coli was greater than against the wild-type (+). There-

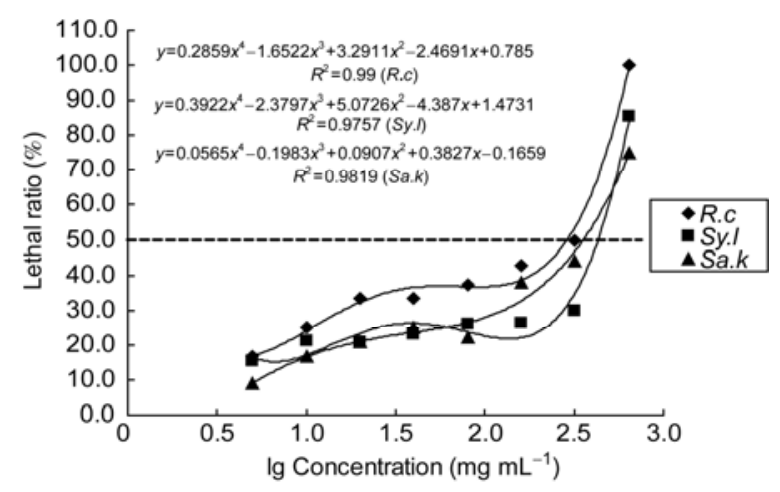

Figure 1 Lethal curves of three active seaweed samples in brine shrimp lethality test (under concentrations higher than $640 \mu \mathrm{g} \mathrm{mL} \mathrm{m}^{-1}$, i.e. at logarithm of concentration higher than 2.8, the lethal ratios all reached $100 \%$ ).

fore, it may have anti-tumor potential via the mechanism of DNA damage and serve as a possible source of anti-tumor drugs. The MICs of Rh.confervoides, Sar. kjellmanianum, and Enteromorpha intestinalis against two E. coli strains were 128 or $64 \mu \mathrm{g} \mathrm{mL}^{-1}$, respectively, which indicated their strong antimicrobial activity and potentials as sources of antibiotic drugs. However, their selectivity values did not all exceed 1 , showing that they may not act by damaging DNA.

Table 3 The bioactivity of seaweeds in DNA damage repair test

\begin{tabular}{|c|c|c|c|c|}
\hline Species & $\begin{array}{l}\text { Inhibition zone against } \\
\text { AB3027 (-) }(\Phi, \mathrm{mm})\end{array}$ & $\begin{array}{c}\text { MIC against } \\
\text { AB1157 (+) }\left(\mu \mathrm{g} \mathrm{mL}^{-1}\right)\end{array}$ & $\begin{array}{c}\text { MIC against } \\
\text { AB3027 }(-)\left(\mu \mathrm{g} \mathrm{mL}^{-1}\right)\end{array}$ & Selectivity \\
\hline Ulva pertusa & - & & & \\
\hline Cladophora fascicularis & - & & & \\
\hline Enteromorpha intestinalis & $11.2 \pm 1.3$ & 64 & 128 & 0.5 \\
\hline Chondrus ocellatus & $13.3 \pm 2.1$ & 512 & 256 & 2 \\
\hline Rhodomela confervoides & - & & & \\
\hline Symphyocladia latiuscula & $18.0 \pm 1.0$ & 128 & 128 & 1 \\
\hline Undaria pinnatifida & - & & & \\
\hline Sargassum kjellmanianum & $12.2 \pm 1.4$ & 64 & 64 & 1 \\
\hline
\end{tabular}




\subsection{HPTLC analysis}

The colorization by $\mathrm{H}_{2} \mathrm{SO}_{4}$-anisaldehyde reagent showed that these seaweeds contained quite diverse metabolites. The grey spots with $R f$ value in the range $0.55-0.73$ should usually be steroids or terpenoids, while the main tailing spots with $R f$ value 0.51 may be some fatty acid derivatives (marked with arrows in Figure 2(a)).

The acid $\mathrm{FeCl}_{3}$ reagent further displayed typical blue spots with $\mathrm{Rf}$ value 0.23 and 0.38 in two red algae $R h$. confervoides (R.C.) and Sym. latiuscula (S.L.) extracts, showing the presence of phenolic compounds (marked with arrows in Figure 2(b)).

\subsection{HPLC-DAD-MS analysis}

Since Symphyocladia latiuscul showed strong bioactivities in all the four assays, its extract was further analyzed by HPLC-DAD-MS. The molecular weight of each main peak was deduced by quasi-molecular peaks in both positive and negative mode mass spectra (Figure 3). Then their molecular weights were used to search the plant metabolites in the Dictionary of Natural Products on DVD (DNP2011) [14]. During the searching, factors like wavelength of maximum UV absorbance or conjugated systems for those hits without UV data, biological resource, polarity's reasonability, and elemental constituents for some obvious halogenated compounds, were taken into account to rule out unreasonable hits. The analysis results are summarized in Table 4.

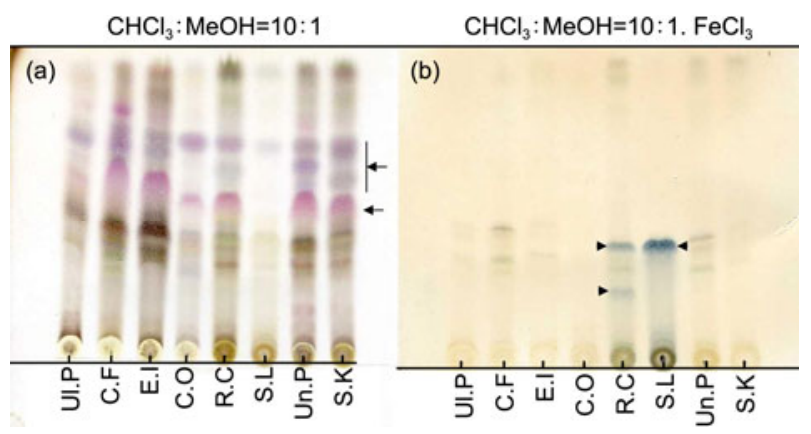

Figure 2 The HPTLC of seaweeds extracts. (a) Dyed by $\mathrm{H}_{2} \mathrm{SO}_{4}$-anisaldehyde; (b) dyed by acid $\mathrm{FeCl}_{3}$ reagent.
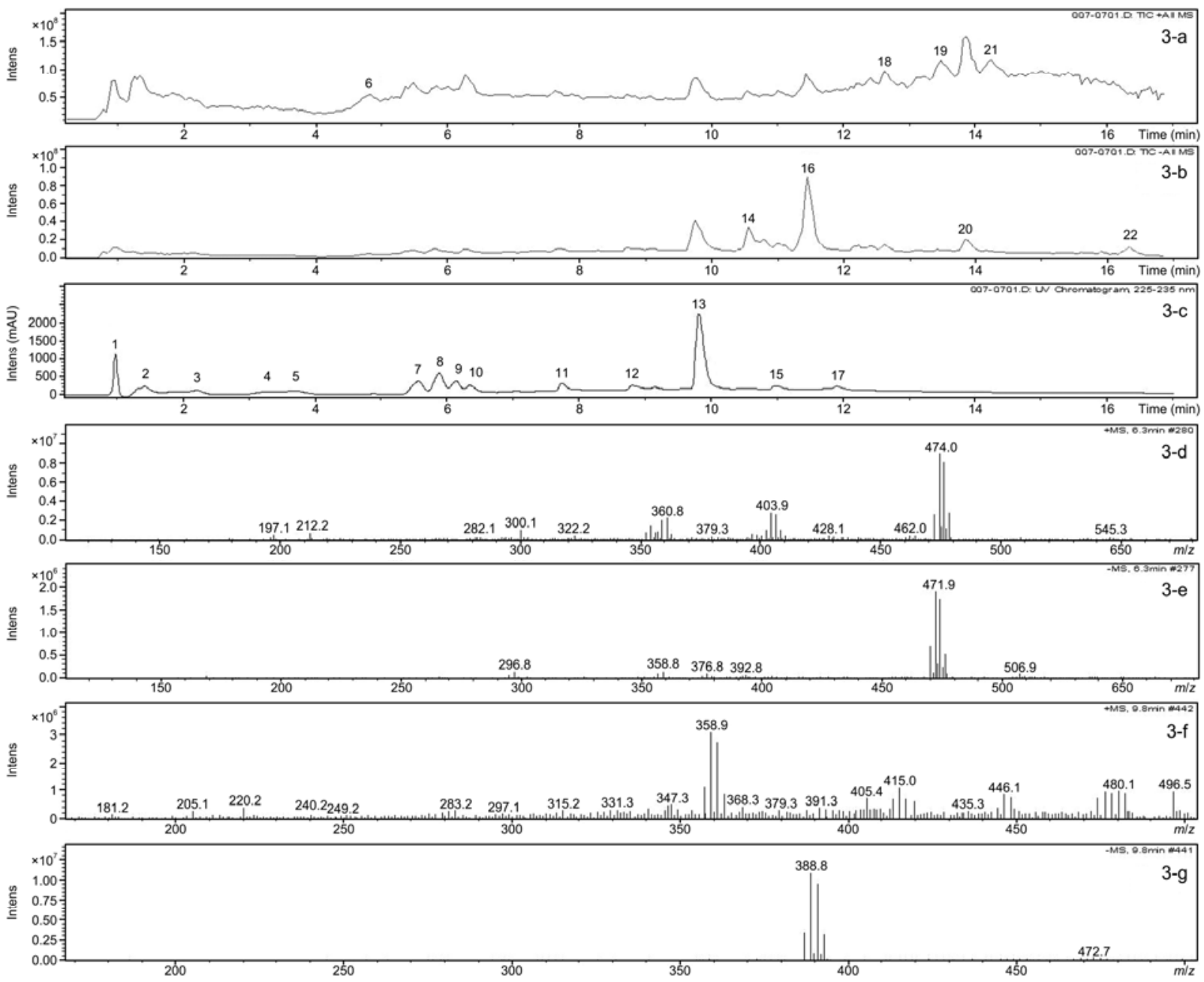

Figure 3 HPLC-DAD-MS of Symphyocladia latiuscula extract. (a) TIC(+); (b) TIC(-); (c) chromatographic spectrum under 224-235 nm; (d)-(e) MS(+) and MS(-) of peak 10; (f)-(g) MS(+) and MS(-) of peak 13. 
Table 4 LC-DAD-MS analysis and database searching of main peaks in Symphyocladia latiuscula extract

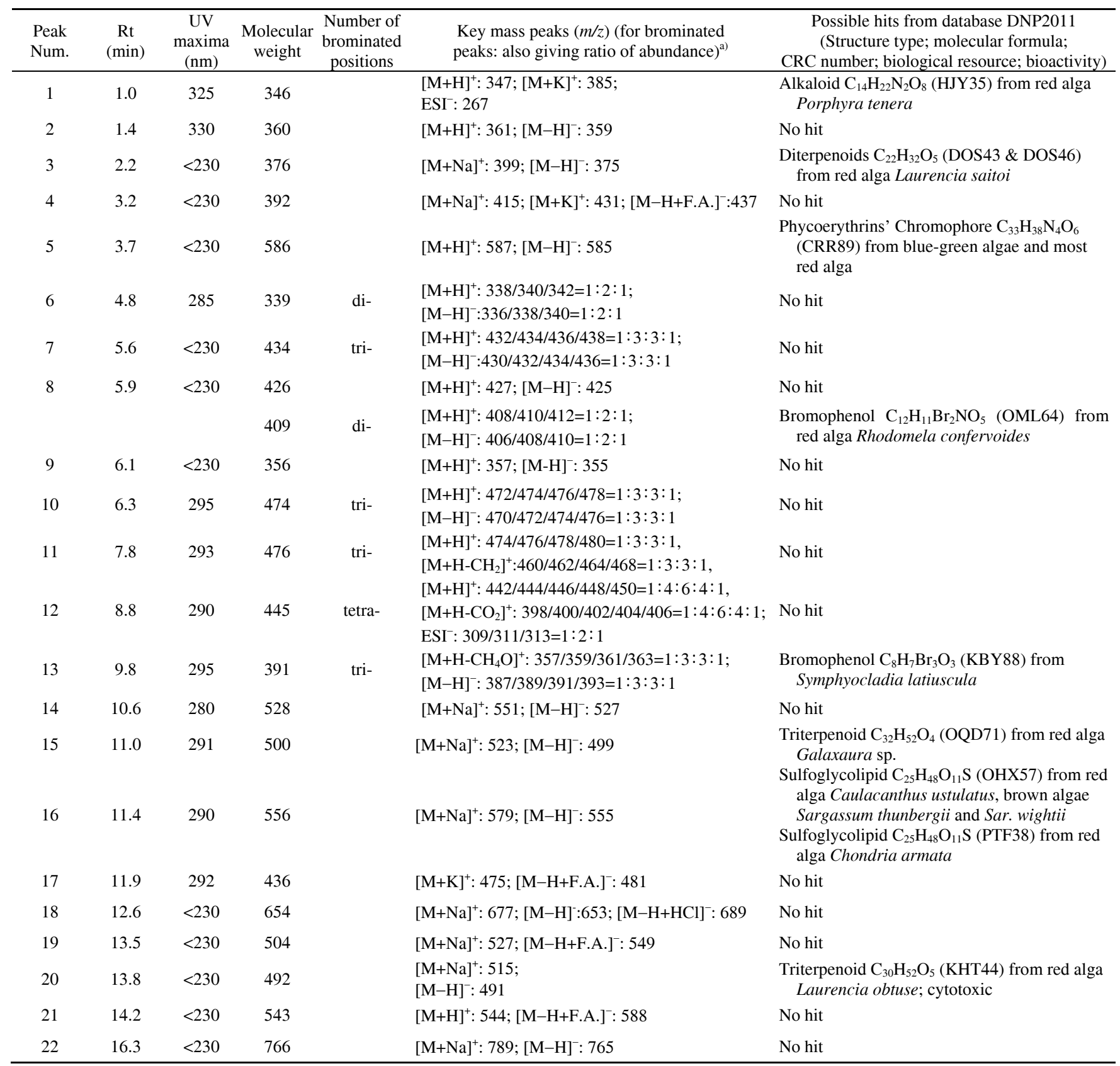

a) F.A.: formic acid.

Among the 22 main peaks, 7 showed obvious mass characteristics of brominated compounds, i.e., isotopic peak clusters with successive mass difference of two Daltons and typical intensity ratios, including $1: 2: 1$ clusters for dibrominated, $1: 3: 3: 1$ for tribrominated, and $1: 4: 6: 4: 1$ for tetrabrominated compounds. Among them, main component of peak 8 and peak 13 may be possibly known metabolites respectively from red algae Rhodomela confervoides and Symphyocladia latiuscul, both of which belong to the family of Rhodomelaceae, a group known for their ability in producing halogenated compounds [15]. The other five peaks may be new brominated natural products.

Besides, six non-brominated peaks' main component showed identical molecular weights, and similar UV and polarity characteristics with some algal metabolites, including alkaloid, diterpenoids, triterpenoids, photosynthetic segment and sulfoglycolipids. One triterpenoid was reported to exhibit cytotoxicity. Additionally, other 10 peaks did not give proper matches in DNP2011 and may be some new natural products.

Of course, if standard substances had been available, thrse known compounds could have been better confirmed by 
comparison of retention times and UV spectra.

\section{Discussion}

As exhibited by the results, the seaweeds under investigation produced large biomass and also showed high biological activity. Sym. latiuscula in Rhodophyta showed strong anti-MRSA and anti-brine shrimp activities, and inhibitory activity against the spore germination of $P$. oryzae; besides, it exhibited remarkable inhibitory activity against the two $E$. coli DDRT strains. Rh. confervoides showed remarkable anti-brine shrimp activity, moderate anti-MRSA activity, and inhibitory activity against the spore germination of $P$. oryzae. Ch. ocellatus showed moderate anti-MRSA activity and strongest selective inhibitory activity against $E$. coli strain AB3027 with defect in DNA damage repair. Sar. kjellmanianum in Phaeophyta exhibited powerful anti-brine shrimp activity, moderate anti-MRSA activity and non-selective activity against (+/-) E. coli strains. However, Un. pinnatifida only showed moderate anti-MRSA activity. As to Chlorophyta, En. intestinalis exhibited anti-E. coli and anti-MRSA activities. $C l$. fascicularis and $U l$. pertusa only inhibited MRSA moderately. In general, the bioactivities of seaweeds from Rhodophyta and Phaeophyta were relatively stronger than those from Chlorophyta.

The seaweeds with anti-MRSA activity or non-selective activity against (+/-) E. coli strains can be used for the development of new drugs to treat infection caused by drugresistant $\mathrm{G}^{+}$bacteria or $\mathrm{G}^{-}$bacteria, respectively. As for the seaweeds possessing both of the two bioactivities, they are potential resources of broad-spectrum antibiotics. To species exhibiting selective inhibitory activity in DDRT, activity against spore germination of $P$. oryzae or anti-brine shrimp larvae activity, they may have potential anti-tumor activity and are expected to serve as sources of new anticancer drugs. Besides, the algae that can inhibit $P$. oryzae or kill brine shrimp larvae may be developed as potential antifungal agents or pesticides for medical and agricultural purposes.

Fan's group has reported the diversified bioactivities of seaweeds in China $[16,17]$. In their reports, the ethyl acetate partitions of alcohol extracts of Sar. kjellmanianum, $R h$. confervoides, and Ul. pertusa collected at Shandong coastline also showed strong anti-Staphylococcus aureus (common test strain) activity; the aqueous partition of Sym. Latiuscula's alcohol extract also inhibited E. coli; the alcohol extracts of Sym. Latiuscula, Rh. confervoides, and Ul. pertusa also exhibited cytotoxicity to cancer cell lines. Likewise, our samples from Dalian coastline also showed similar or related activities except that Ul. Pertusa from Dalian did not show significant activity as the same Shandong species did. However, in our test, these seaweeds also showed anti-drug resistant Staphylococcus aureus, anti-fungal, and pesticidal ability.

In our preliminary investigation on their chemical con- stituents, the HPTLC results showed that these seaweeds can produce quite diverse metabolites and red algae $R h$. confervoides and Sym. latiuscula were also found to contain phenolic compounds. HPLC-DAD-MS analysis suggested that Sym. Latiuscula, with the broadest strong activity in present assays, may contain different types of known or new metabolites, including rich brominated compounds such as two known brominated phenols. There are lots of reports on bioactivity of marine halogenated compounds [15]. So, it is possible that the strong bioactivity of Sym. latiuscula has some relationship with its rich brominated metabolites.

In the past decades, there have been more and more reports on bioactivity of seaweeds. For example, Sar. kjellmanianum displayed antioxidant effect [18]; Rh. confervoides and Sym. latiuscula showed anti-tumor, antibacterial and antioxidant activities [16]. However, their advantages have not been fully utilized till now. Un. pinnatifida is widely cultivated but is only used to produce food up to now. Sar. kjellmanianum also has large biomass in the Yellow Sea region, but is only used as the raw material of algin industry. If their biomedical and agrichemical applications can be fully exploited, the high value utilization will be greatly promoted. En. intestinalis is widely distributed along coastlines. Enteromorpha species often multiply at a surprising rate when the condition is appropriate. Since 2008, green tides caused by overgrowing Enteromorpha species occurred nearly every summer in Qingdao, China, and researchers have begun to develop ways to turn wastes into wealth. In our study, we found that En. intestinalis may be used as source of antibiotics.

\section{Conclusion}

In the current study, the common seaweeds from Dalian coastline of the North Yellow Sea were found to yield considerable biomass and some natural constituents with remarkable antibacterial, antifungal, and larvicidal activities as well as possible antitumor potentials. By natural collection or artificial cultivation, their sustainable supply can be ensured, which lays the basis for further chemical research on and sustainable exploitation of their bioactive constituents for medicinal and agrichemical purposes. Furthermore, some waste or harmful algae can also produce wealth. Thus, their higher value utilization is expected in the future.

This work was supported by the National Natural Science Foundation of China (20902009), Postdoctoral Science Foundation of China (2011M500051 and 2012T50242), the Key Laboratory of Experimental Marine Biology, Institute of Oceanology, Chinese Academy of Sciences ( $k f 201009)$ and the Scientific and Technological Fund of Dalian (2008J23JH041). The authors thank Prof. Stephanie Grond in University of Tübingen in Germany for her financial help on LC-MS measurement.

1 Li P, Gao P, Wang J X. The research of bioactive substances from marine microorganisms (in Chinese). Hebei Fisheries, 2009, (2): 
43-47

2 McMinn A, Martin A, Ryan K. Phytoplankton and sea ice algal biomass and physiology during the transition between winter and spring (McMurdo Sound, Antarctica). Polar Biol, 2010, 33: 15471556

3 Shan W R, Li J X, Liu H F. Study on the inhibitory effects of different active materials screened by the filter paper on cotton verticillium wilt (in Chinese). Chin Agricult Sci Bull, 2010, 26: 285-289

4 National Committee for Clinical Laboratory Standards. Methods for dilution antimicrobial susceptibility tests for bacteria that grow aerobically. Approved Standard. 6th Ed. NCCLS document M7-A6. Wayne, Pennsylvania: NCCLS, 2003

5 Zhang Y, Mu J, Han J Y, et al. An improved brine shrimp larvae lethality microwell test method. Toxicol Mechan Methods, 2012, 22: 23-30

6 Kobayashi H, Namikoshi M, Yoshimoto T, et al. A screening method for an antimitotic and antifungal substances using conidia of Pyriculavia oryzae, modification and application to tropicalsarine fungi. $\mathrm{J}$ Antibiot, 1996, 49: 873-879

7 Alam M Z, Ahmad S, Malik A. Genotoxic and mutagenic potential of agricultural soil irrigated with tannery effluents at Jajmau (Kanpur), India. Arch Environ Contam Toxicol, 2009, 57: 463-476

8 Shao K S, Li X Y. Seasonal variation of benthic seaweed community in the intertide in Dalian (in Chinese). J Dalian Fisheries University, 2000, 15: 29-34

9 Wang L, Li W P, Liu B, et al. Research progress methicillin-resistant
Staphylococcus aureus (in Chinese). Chin Nurs Res, 2011, 25: 16951697

10 Manilal A, Sujith S, Kiran G S, et al. Biopotentials of seaweeds collected from southwest coast of India. J Marine Sci Technol, 2009, 17: 67-73

11 Meyer B N, Ferrigni N R, Putnam G E, et al. Brine shrimp: A convenient general bioassay for active plant constituents. Plant Med, 1982, 45: 31-34

12 Hu Z Y, Liu S Z, Huang H, et al. A rapid screening assay for insecticidal antibiotic produced by marine actinomycetes (in Chinese). Mar Sci Bull, 2000, 19: 36-41

13 Yang C Y. A contrastive study of the screening of endophytic fungi for anticancer activity with the methods of the saline shrimp and A549 cancer cell (in Chinese). J Yunnan Univ National (Nat Sci), 2009, 18: 250-254

14 Buckingham J. Dictionary of Natural Products on DVD. London, UK: Chapman and Hall/CRC, 2011

15 Cabrita M T, Vale C, Rauter A P. Halogenated compounds from marine algae. Mar Drugs, 2010, 8: 2301-2317

16 Xu X L, Fan X, Song F H. Study on bioactivity of Chinese marine alga extracts (in Chinese). Oceanol Limnol Sin, 2004, 35: 55-63

17 Xu N J, Fan X, Han L J, et al. Study on the antibacterial activities of the ethanol extracts of seaweed (in Chinese). Oceanol Limnol Sin, 2002, 33: 265-270

18 Tian Y Y, Yu J. Progress in research on brown seaweed in medicine and food (in Chinese). Mar Sci Bull, 1996, 15: 81-86

Open Access This article is distributed under the terms of the Creative Commons Attribution License which permits any use, distribution, and reproduction in any medium, provided the original author(s) and source are credited. 